\title{
Serial Arterial Lactate Clearance and Outcome in Patients with Cardio-respiratory Insufficiency Presenting in Emergency Ward at Tertiary Level Hospital
}

\author{
Siddharth Dhoj Khati ${ }^{1, ~}$, Bishal Pokhrel², Rekha Karki ${ }^{3}$ \\ ${ }^{1}$ Department of General Practice and Emergency Medicine, Karnali Academy of Health Sciences, Jumla, Nepal \\ ${ }^{2}$ Department of Community Medicine and Public Health, Karnali Academy of Health Sciences, Jumla, Nepal \\ ${ }^{3}$ Medical Officer, Karnali Academy of Health Sciences, Jumla, Nepal
}

Email address:

sidkhati59@gmail.com (S. D. Khati)

${ }^{*}$ Corresponding author

\section{To cite this article:}

Siddharth Dhoj Khati, Bishal Pokhrel, Rekha Karki. Serial Arterial Lactate Clearance and Outcome in Patients with Cardio-respiratory Insufficiency Presenting in Emergency Ward at Tertiary Level Hospital. Journal of Family Medicine and Health Care.

Vol. 6, No. 3, 2020, pp. 83-86. doi: 10.11648/j.jfmhc.20200603.15

Received: June 12, 2020; Accepted: June 28, 2020; Published: July 13, 2020

\begin{abstract}
Introduction: Acute cardio-respiratory failure is one of the acute common problems encountered in emergency and which required immediately intervention. It creates an imbalance between energy supply, demand, and consumption. Earlier lactate clearance should be useful to identify patient able to reverse the metabolic derangement and failure to rapidly resolve the oxygen debt, indicated by poor lactate clearance, would be correlated with negative outcome. For this purpose lactate clearance at 2 hour is more useful. Methods: This was a prospective study conducted at B. P. Koirala Institute of Health Sciences, Dharan, Nepal. Preliminary diagnosis was made according to clinical history, physical examination, arterial blood gas and chest radio graph. A national emergency warning system was used for patient evaluation. Gas exchange and lactate blood concentration was assessed at Emergency ward at arrival, $2 \& 6 \mathrm{hr}$. Two-hour lactate clearance was calculated as (Lactate start - lactate 2 hour)/lactate start (\%). Blood gas-analysis and arterial lactate was performed by intermittent blood sampling and co-oximetry. Results: Out of 74 patients the COPD was the most common co-morbidity condition $(25.7 \%)$, followed by congestive heart failure (18.9\%). Comprising of lactate clearance at two hours and the lactate clearance at six hours, the lactate clearance at two hours and its outcomes was more significant $(\mathrm{P}=0.001$, $\mathrm{OR}=10.133)$ than lactate clearance at six hours $(\mathrm{P}=0.213)$. Conclusions: Early lactate clearance was associated with positive outcome rather than late clearance.
\end{abstract}

Keywords: Acute Cardio-respiratory Failure, ABG, AF, ATP, BPKIHS

\section{Introduction}

Acute cardio-respiratory failure is one of the acute common problems encountered in emergency department and which required immediately intervention. Acute cardiac failure is defined as a condition with decreased tissue perfusion other than simple hypovolemia. Respiratory failure is defined as oxygen saturation of less than $90 \%$ despite supplementary oxygen with or without hypercapnia [1].

Acute cardio-respiratory failure from any cause creates an imbalance between energy supply, demand, and consumption. A high lactate concentration associated with a low blood $\mathrm{pH}$ is useful to depict the gravity of such a mismatch. Earlier lactate clearance should be useful to identify patient able to reverse the metabolic derangement and failure to rapidly resolve the oxygen debt, indicated by poor lactate clearance, would be correlated with negative outcome. For this purpose lactate clearance at 2 hour is more useful [1]. Following the concept of "Early-Goal-Directed-Therapy one should be satisfied if therapeutic approach determines a lactate clearance greater than $20 \%$ within 6 hour of treatment as in septic patients. However, lactate 6 hour clearance is less useful in assessing the response to treatment [2].

An earlier lactate clearance should be useful to identify 
patient able to reverse the metabolic derangement and failure to rapidly resolve the oxygen debt, indicated by poor lactate clearance, would be correlated with negative outcome. For this purpose lactate clearance at 2 hour is more useful [1].

The burden of cardio-respiratory failure if high worldwide and also in Nepal so, we designed this study for immediate management to reduce morbidity and mortality for the patients.

\section{Methods}

This was observational prospective, cross-sectional study conducted at Emergency ward of B. P. K. I. H. S, Dharan, Nepal from September 2017 to August 2018. Written consent was taken. Patient of age more than 16 years presented at Emergency ward of B. P. K. I. H. S was included. The preliminary diagnosis was made according to clinical history, physical examination, arterial blood gas and chest radio graph. A national emergency warning system was used for patient evaluation. Gas exchange and lactate blood concentration was assessed at Emergency ward at arrival, 2 \& $6 \mathrm{hr}$. Two-hour lactate clearance was calculated as (Lactate start - lactate 2 hour)/lactate start (\%). Blood gas-analysis and arterial lactate was performed by intermittent blood sampling and co-oximetry (Radiometer ABL 800). All patients were treated according to standard practice in our Emergency Ward of BPKIHS.

As per the guidelines given by society of critical care medicine $<20 \%$ lactate clearance at 2 hours was calculated and then compared with outcome. Positive outcome measures were discharge or transfer to general ward and negative outcome were mortality or admission to Medical Intensive ward. Their clinical and investigative data were compiled and analysed based on the following factors: Age/sex, Blood pressure, heart rate, respiratory rate, oxygen saturation, Temperature, Level of consciousness, ABG, WBC, HCT\%, $\mathrm{ECG}, \mathrm{CXR}$, creatinine, lactate at start, $2 \& 6 \mathrm{hr}$, lactate clearance after $2 \& 6$ hours.

Sample size was calculated by: $\mathrm{N}=\mathrm{Z}^{2} \mathrm{pq} / \mathrm{L}^{2}=(1.96)^{2} \times 30.53$ x $69.47 / 6.12$ x 6.12. $\mathrm{N}=218$

The appropriate sample size in the study is 218 at $95 \%$ Confidence Interval. According to hospital record data, total patient with Cardio-respiratory failure $(2016)=57$. Total patient with Congestive heart failure $(2016)=53$. So, total eligible cases with a year $\mathrm{No}=110$. Calculating sample size for finite population:

$$
\mathrm{n}=\mathrm{N} /(1+\mathrm{N} / \mathrm{No})=218 /(1+218 / 110)=73.15=74
$$

So, by using above formula, the sample size of this study (n) is 74 .

Descriptive statistics of demographic and laboratory variables were calculated with mean percentages, $\mathrm{P}$ value and Odd Ratio.

\section{Results}

The age rang of the patient were 17 to 98 years and the mean age was Male: Female=57.42 +/- 18.945 years.

Among 74 cases the chronic obstructive airway diseases was the most common co-morbidity $(25.7 \%)$ followed by Congestive failure $(18.9 \%)$ in the patients.

Table 1. Co-morbidities of the patients with cardio respiratory.

\begin{tabular}{llll}
\hline Characteristics & Frequency & Percent \\
\hline & Atrial fibrillation & 2 & 2.7 \\
& Asthma & 4 & 5.4 \\
& Carcinoma bronchus & 1 & 1.4 \\
& CAD & 14 & 18.9 \\
Co-morbidity & CCF & 14 & 18.9 \\
& COPD & 19 & 25.7 \\
& Diabetes mellitus & 3 & 4.1 \\
& Hypertension & 1 & 1.4 \\
& VHD & 7 & 9.5 \\
& No history & 9 & 12.2 \\
\hline
\end{tabular}

More than half of the patient with MI and CCF and COPD presenting with cor-pulmonale had positive outcome, ratio of negative outcome: positive outcome was $0.7: 1$ in cases of MI, 0.5:1 among CCF patients and 0.26:1 in COPD presenting with cor-pulmonale patients, among 16 cases of MI 7 cases (43.8\%) had positive outcome and 9 cases (56.3\%) had negative outcome, among 17 cases of CCF 6 cases $(35.3 \%)$ had negative outcome and 11 cases $(64.7 \%)$ had positive outcome, among 19 cases of COPD presenting with cor- pulmonale 4 cases $(21.1 \%)$ had negative outcome and 15 cases $(78.9 \%)$ had positive outcome. But, on comparing these diseases with outcomes their association were not significant.

Table 2. Comparison of lactate level outcome with underlying diseases leading to cardio respiratory insufficiency.

\begin{tabular}{|c|c|c|c|c|}
\hline Characteristics & Negative outcome & Positive outcome & Odd ratio & $\mathbf{p}$ \\
\hline Myocardial infraction & $\begin{array}{l}7 \\
(43.8 \%)\end{array}$ & $\begin{array}{l}9 \\
(56.3 \%)\end{array}$ & $\begin{array}{l}2.230 \\
(7.037-0.706)\end{array}$ & 0.218 \\
\hline characteristics & Negative outcome & positive outcome & Odd ratio & $\mathrm{p}$ \\
\hline $\mathrm{CCF}$ & $\begin{array}{l}6 \\
(35.3 \%)\end{array}$ & $\begin{array}{l}11 \\
(64.7 \%)\end{array}$ & $\begin{array}{l}0.585 \\
(0.179-1.912)\end{array}$ & 0.372 \\
\hline COPD presenting with cor-pulmonale & $\begin{array}{l}4 \\
(21.1 \%)\end{array}$ & $\begin{array}{l}15 \\
(78.9 \%)\end{array}$ & $\begin{array}{l}0.548 \\
(1.891-1.891)\end{array}$ & 0.397 \\
\hline
\end{tabular}

Lactate clearance at six hours and outcome were also compared and six hour lactate clearance was insignificant $(\mathrm{P}=0.213)$. 
Table 3. Comparison of the lactate clearance at six hours between positive and negative outcome group.

\begin{tabular}{llllll}
\hline Characteristics & & Negative outcome $(\mathbf{n}=\mathbf{2 2})$ & Positive outcome $(\mathbf{n}=\mathbf{5 2})$ & Odd ratio & P \\
\hline Lactate & \multirow{2}{*}{$\begin{array}{l}\text { clearance at } \\
\text { six hours }\end{array}$} & $(35.7 \%)$ & 27 & & \\
& $>20 \%$ & 7 & $(64.3 \%)$ & $1.984(5.665-0.695)$ & 0.213 \\
& $(21.9 \%)$ & 25 & & \\
\hline
\end{tabular}

Lactate clearance at two hours and outcome were compared and two hour lactate clearance was significant in predicting outcomes (p 0.001$) \mathrm{OR}=10.133$ (38.688-2.654).

Table 4. Comparison of the lactate clearance at two hours between positive and negative outcome group.

\begin{tabular}{|c|c|c|c|c|c|}
\hline Characteristic & & Negative outcome $(n=22)$ & Positive outcome $(n=52)$ & Odd ratio & $\mathbf{P}$ \\
\hline $\begin{array}{l}\text { Lactate } \\
\text { clearance at } \\
\text { two hours }\end{array}$ & $\begin{array}{l}<20 \% \\
>20 \%\end{array}$ & $\begin{array}{l}19 \\
(48.7 \%) \\
3 \\
(8.6 \%)\end{array}$ & $\begin{array}{l}20 \\
(51.3 \%) \\
32 \\
(91.4 \%)\end{array}$ & $10.133(38.688-2.654)$ & 0.001 \\
\hline
\end{tabular}

The Lactate clearance at two hours \& mortality were compared which shows statistically significant. $\mathrm{P}=0.012 \mathrm{OR}=0.821(0.95-0.78)$.

Table 5. Comparison of the lactate clearance at two hours between mortality groups.

\begin{tabular}{|c|c|c|c|c|}
\hline Characteristics & & & Odd ratio & $\mathbf{P}$ \\
\hline Lactate Clearance & Mortality & Non mortality & \multirow[b]{2}{*}{$0.821(0.95-0.78)$} & \multirow[b]{2}{*}{0.012} \\
\hline $\begin{array}{l}<20 \% \\
>20 \%\end{array}$ & $\begin{array}{l}7(17.9 \%) \\
0\end{array}$ & $\begin{array}{l}32(82.1 \%) \\
35(100 \%)\end{array}$ & & \\
\hline
\end{tabular}

Lactate clearance at six hours \& mortality were compared and showed statistically insignificant $\mathrm{p}=0.691$ in our study.

Table 6. Comparison of the lactate clearance at six hours between mortality groups.

\begin{tabular}{|c|c|c|c|c|}
\hline Characteristics & & & Odd ratio & $\mathbf{P}$ \\
\hline Lactate Clearance & Mortality & Non mortality & \multirow{3}{*}{$2.027(11.197-.367)$} & \multirow{3}{*}{0.691} \\
\hline$<20 \%$ & $5(11.9 \%)$ & $37(88.1 \%)$ & & \\
\hline$>20 \%$ & $2(6.3 \%)$ & 30 (93.8\%) & & \\
\hline
\end{tabular}

\section{Discussion}

Cardiac and Respiratory failure seemed to be common presentation to emergency department of Nepal. Only few studies done in Nepal that touched upon cardio Respiratory failure and also lactate and its clearance in Emergency Department. But there was only few studies has showed Lactate clearance at two hours has high effectiveness than Lactate clearance at six hours.

A Study conducted among 265 cases admitted had coronary artery diseases (36.5\%) 93 cases as a major cause of heart failure followed by Rheumatic heart diseases 65 $(25.5 \%)$ cases, the commonest presenting problem among them was shortness of breath (81\%) followed by leg swelling $56 \%{ }^{4}$. In another study among 95 patient with cardio respiratory insufficiency 63 cases had ischemic heart diseases followed by 39 cases with COPD as a major cause of cardiorespiratory failure [1]. Our study shows similar result and showed Chronic Obstructive Pulmonary Diseases presenting with corpulmonale 19 cases $(25.7 \%)$ as a major cause of cardio respiratory insufficiency $(\mathrm{n}=74)$ followed by myocardial infarction 16 cases $(21.6 \%)$. Our study found shortness of breath $42(56.8 \%)$ followed by chest pain 13 $(17.6 \%)$ as common presenting problem.

The mean age of cardio respiratory insufficient patients in our study was $57.42 \pm 18.945$ years which was lower than [1, 3 ] and higher than ${ }^{4}$. In our study Male: Female ratio was
1:1.3 which was as similar as most of the studies [1, 3-6]. In our study the most frequent co-morbidities were COPD 19 cases $(25.7 \%)$ followed by heart failure 14 cases $(18.9 \%) \&$ coronary artery disease 14 cases $(18.9 \%)$ other study also showed similar results $[3,4]$.

In our study 39 cases $(52.7 \%$ ) had lactate clearance $<20 \%$ at two hours and on calculating the proportion of lactate clearance with outcomes 19 cases (48.7\%) had negative outcome which was less than 20 cases ( $\mathrm{n}=95)$ [7] and 20 cases $(51.3 \%)$ had positive outcome which was high than 9 cases $(n=95)[1]$.

Similar study done on lactate clearance and outcome lactate clearance $<20 \%$ was associated with negative outcome (mortality or intubation) (OR 16.11 (6.53-39.70) $\mathrm{p}<0.5)$

Other study supported the same evidence $[1,2,7,8]$. Our study also showed relation between delayed lactate clearance $<20 \%$ at 2 hours and adverse outcomes $(\mathrm{OR}=10.133$ (38.6682.654) $\mathrm{p}=0.001)$ as well as delayed lactate clearance $<20 \%$ at two hours with mortality at emergency $(\mathrm{OR}=0.821(0.95$ 0.78) $\mathrm{p}=0.012$ )

A Scoring System formulated at Royal College of Physician postulated a scoring system NEWS depending upon triage vitals and was stratified according to risk group and was significant $\mathrm{P}=0.89$ (95\% CI: 0.880-0.895) [9], our study also showed adverse outcome associated with NEWS high risk (OD (8.889 (26.756-2.847) $\mathrm{p}=0.001)$ [9].

Our study also showed lactate clearance $<20 \%$ at two 
hours was independently associated high risk outcome with respect to NEWS (OR $3.53(9.738-1.226) \mathrm{P}<0.05)$ but was not associated with lactate clearance at six hours in respect to NEWS $\mathrm{p}>0.05$.

\section{Conclusion}

Early lactate clearance was associated with positive outcome rather than late clearance. Chronic obstructive airway diseases were the most common co-morbidity followed by Congestive cardiac failure in the patients with Cardio Respiratory insufficiency. Shortness of breath and chest pain was the most frequent initial presenting complains. Myocardial Infarction had the highest number of negative outcome followed by Congestive Cardiac Failure and Chronic Obstructive airway Diseases presenting with cor pulmonale had highest number of Positive outcome followed by Congestive Cardiac Failure on assessing lactate level outcomes.

\section{Acknowledgements}

I want to express special thanks to HOD, Department of General Practice \& Emergency Medicine, Professor Dr. Gyanendra Bdr. Malla, BPKIHS, Dharan, Professor Dr. Bijendra Kumar Rai, Assistant Professor Dr. Ajay Kumar Yadav and special thank to those entire patient who allow me to participate them in the study.

\section{References}

[1] Defrances CJ, Ph D, Lucas CA, Buie VC, Golosinskiy A. 2006 National Hospital Discharge Survey. 2008.
[2] Dubey L, Sharma SK, Chaurasia AK. Clinical profile of patients hospitalized with heart failure in Bharatpur, Nepal. J Cardiovasc Thorac Res. 2012; 4 (4): 103-5.

[3] Jacobsen G, Muzzin A, Ressler JA, Tomlanovich MC. Early lactate clearance is associated with improved outcome in severe sepsis and septic shock*. Crit Care Med. 2004; 32 (8).

[4] Kruse O, Grunnet N, Barfod C. Blood lactate as a predictor for in-hospital mortality in patients admitted acutely to hospital: a systematic review. Scand J Trauma Resusc Emerg Med [Internet]. 2011; 19 (1): 74. Available from: http://www.sjtrem.com/content/19/1/74.

[5] Nguyen HB, Loomba M, Yang JJ, Jacobsen G, Shah K, Otero $\mathrm{RM}$, et al. Early lactate clearance is associated with biomarkers of inflammation, coagulation, apoptosis, organ dysfunction and mortality in severe sepsis and septic shock. J Inflamm. 2010; 7 (6): 1-11.

[6] Pnadey R, Chokhani R, N B KC. Use of non invasive ventilation in patients with respiratory failure in Nepal. [Internet]. 2011. p. 256-9. Available from: http://ovidsp.ovid.com/ovidweb.cgi?T=JS\&PAGE=reference $\& \mathrm{D}=$ medl\&NEWS $=\mathrm{N} \& \mathrm{AN}=22710534$.

[7] Scott S, Antonaglia V, Guiotto G, Paladino F, Schiraldi F. Two-hour lactate clearance predicts negative outcome in patients with cardiorespiratory insufficiency. Crit Care Res Pract. 2010; 917053: 6.

[8] Vincent J-L, Akça S, De Mendonça A, Haji-Michael P, Sprung $\mathrm{C}$, Moreno R, et al. The epidemiology of acute respiratory failure in critically ill patients $(*)$. Clin Investig Crit care. 2002; 121 (1609): 1602-9.

[9] National Early Warning Score National Early Warning Score (NEWS) 2. 2017.

[10] Bakker J, Jansen TC. Don ' $t$ take vitals, take a lactate. Intensive Care Med. 2007; 33: 1863-5. 